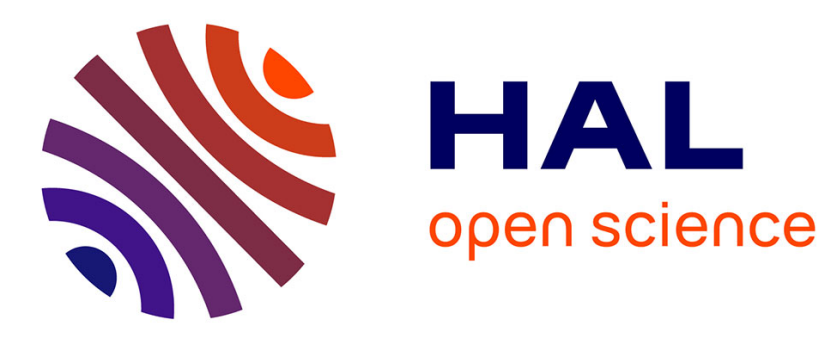

\title{
Brittle damage in initially anisotropic materials: a model accounting for the induced anisotropy and unilateral effects
}

Hélène Welemane, Cristina Goidescu, Djimédo Kondo, Olivier Pantalé, Moussa Karama

\section{To cite this version:}

Hélène Welemane, Cristina Goidescu, Djimédo Kondo, Olivier Pantalé, Moussa Karama. Brittle damage in initially anisotropic materials: a model accounting for the induced anisotropy and unilateral effects. Applied Mechanics and Materials, 2015, vol. 784, pp. 173-178. 10.4028/www.scientific.net/AMM.784.173 . hal-01212114

\section{HAL Id: hal-01212114 \\ https://hal.science/hal-01212114}

Submitted on 6 Oct 2015

HAL is a multi-disciplinary open access archive for the deposit and dissemination of scientific research documents, whether they are published or not. The documents may come from teaching and research institutions in France or abroad, or from public or private research centers.
L'archive ouverte pluridisciplinaire HAL, est destinée au dépôt et à la diffusion de documents scientifiques de niveau recherche, publiés ou non, émanant des établissements d'enseignement et de recherche français ou étrangers, des laboratoires publics ou privés. 


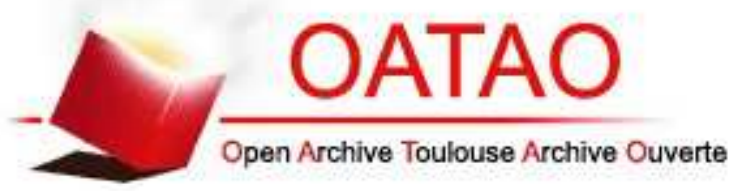

\section{Open Archive Toulouse Archive Ouverte (OATAO)}

OATAO is an open access repository that collects the work of Toulouse researchers and makes it freely available over the web where possible.

This is an author-deposited version published in: http://oatao.univ-toulouse.fr/ Eprints ID: 14228

To link to this article: DOI:10.4028/www.scientific.net/AMM.784.173 http://dx.doi.org/10.4028/www.scientific.net/AMM.784.173

\section{To cite this version:}

Welemane, Hélène and Goidescu, Cristina and Kondo, Djimédo and Pantalé, Olivier and Karama, Moussa Brittle damage in initially anisotropic materials: a model accounting for the induced anisotropy and unilateral effects. (2015) Applied Mechanics and Materials, vol. 784. pp. 173-178. ISSN $\underline{1660-9336}$ 


\title{
Brittle damage in initially anisotropic materials: a model accounting for the induced anisotropy and unilateral effects
}

\author{
WELEMANE Hélène ${ }^{1, a^{*}}$, GOIDESCU Cristina ${ }^{1, b}$, KONDO Djimédo $^{2, c}$, \\ PANTALE Olivier ${ }^{1, d}$ and KARAMA Moussa ${ }^{1, e}$ \\ ${ }^{1}$ Université de Toulouse, Ecole Nationale d'Ingénieurs de Tarbes, INP/ENIT, 47 avenue d'Azereix, \\ F-65016 Tarbes \\ ${ }^{2}$ Université Paris VI, Institut d'Alembert, 4 place Jussieu, F-75252 Paris \\ ahelene.welemane@enit.fr, ${ }^{b}$ cristina.goidescu@gmail.com, 'cdjimedo.kondo@upmc.fr, \\ dolivier.pantale@enit.fr, ${ }^{\mathrm{d}}$ moussa.karama@enit.fr \\ ${ }^{*}$ corresponding author
}

Keywords: brittle damage, micromechanical model, initial anisotropy, induced anisotropy, unilateral effect.

\begin{abstract}
A new micromechanical modelling approach for brittle damage in initially orthotropic materials is presented. The proposed strain-based energy formulation allows to derive a fully anisotropic multilinear model for microcracked materials with arbitrary oriented defects. The thermodynamics framework provides a standard procedure for the damage evolution law. The new model explicitly accounts for the interaction between primary and induced anisotropies. Moreover, the very challenging issue of opening-closure effects (unilateral behavior) is addressed in this framework.
\end{abstract}

\section{Introduction}

The mechanical behavior of several engineering materials is governed by microcracking. Main macroscopic consequences induced by these specific defects are elastic properties degradation, loadinduced anisotropy and microcracks opening-closure effects (also called unilateral effects), that have been put in evidence experimentally on different materials (see for instance [1-3] for composites, [4] for concretes or [5,6] for sedimentary rocks).

For many applications (mechanics, aeronautics, geomechanics, etc), it is then required to model such degradation process to derive a reliable evaluation of industrial systems. Continuum Damage Mechanics offers an appropriate theoretical framework to account for the inelastic response associated to such features. Yet, some difficulties clearly arise in the brittle case. First, the simultaneous representation of induced anisotropy and unilateral effects often leads to inconsistencies in the models formulation (see discussions of [7-9] on the admissibility of constitutive laws). Moreover, the recovery phenomenon induced by the closure of microcracks generally lacks of experimental characterization. Finally, accounting for these phenomena in the context of initially anisotropic materials constitutes an even more challenging issue.

Following fundamental idea developed for instance by [10,11], micromechanical approaches provide interesting solutions for these questions. We present in this paper a $2 \mathrm{D}$ approach recently developed in this sense by Goidescu et al. [12]. This model is based on the one hand on closed-form expressions of the overall free energy of microcracked orthotropic media established by means of an homogenization analysis [13]. Thermodynamical arguments, especially the standard framework, help to complete the damage evolution law of the formulation. After a brief recall of the general assumptions of the model, various illustrations are presented on several brittle materials. 


\section{General assumptions and state variables}

We consider here small strain, rate independent and isothermal conditions. Evolution by microcrack growth is assumed to be the only dissipative mechanism. Non interaction, dilute concentration and frictionless conditions are assumed for microcracks.

Total strain tensor $\varepsilon$ is chosen as the observable variable. In relation with the micromechanical basis [13] of this work, a discrete approach is considered for the damage description. The set of scalar variables $\mathbf{d}=\left(d_{i}\right)_{i=1, N}$, with $d_{i}$ the microcrack density of the $\mathrm{i}^{\text {th }}$ microcrack system, is assumed to be the damage internal variable. Orientations $\mathbf{n}_{i}$ (unit normal to the $\mathrm{i}^{\text {th }}$ system of parallel microcracks) are regularly distributed and number $N$ of systems has to be defined according to the accuracy desired for the density description. It should be underlined that microcracks orientations are thus not restricted to initial structural axes.

\section{Thermodynamic potential}

We assume the existence of a thermodynamic potential $W$ (free energy), depending on the state variables $(\varepsilon, \mathbf{d})$.

In the virgin state, the material exhibits an elastic linear behavior with orthotropic symmetry defined by the orthonormal basis $\left(\mathbf{e}_{1}, \mathbf{e}_{2}\right)$. In what follows, we denote by $W_{0}(\varepsilon, \mathbf{A})$ the free energy of the material without damage, with second tensor $\mathbf{A}=\mathbf{e}_{1} \otimes \mathbf{e}_{1}$ accounting for initial anisotropy.

Homogenization procedure used to derive the macroscopic free energy corresponding to 2D initially orthotropic materials weakened by arbitrarily oriented microcracks systems is fully described in [13]. It is important to note that such expression comes essentially from the application of the Hill lemma in the context of cracked bodies and the use of crack displacements expressions in the context of anisotropic elasticity. Accordingly, the general form of the thermodynamic potential is the following one:

$$
W(\varepsilon, \mathbf{d})=W_{0}(\varepsilon, \mathbf{A})+\sum_{i=1}^{N} d_{i} h\left(\varepsilon, \mathbf{A}, \mathbf{n}_{i}\right)
$$

where function $h$ specifies the nature of the energetic contribution of each microcracks system. First, it accounts for the unilateral behavior of microcracks by taking two different forms whether microcracks are open or closed:

$$
h\left(\varepsilon, \mathbf{A}, \mathbf{n}_{i}\right)= \begin{cases}h^{\text {open }}\left(\varepsilon, \mathbf{A}, \mathbf{n}_{i}\right), & \text { if } g\left(\varepsilon, \mathbf{A}, \mathbf{n}_{i}\right)>0 \\ h^{\text {clos }}\left(\varepsilon, \mathbf{A}, \mathbf{n}_{i}\right), & \text { if } g\left(\varepsilon, \mathbf{A}, \mathbf{n}_{i}\right) \leq 0\end{cases}
$$

in which function $g$ defines the opening-closure criterion for microcracks. Moreover, function $h$ introduces various interaction modes between initial and induced anisotropies:

$$
h^{j}\left(\varepsilon, \mathbf{A}, \mathbf{n}_{i}\right)=h_{1}^{j}(\varepsilon, \mathbf{A})+h_{2}^{j}\left(\varepsilon, \mathbf{n}_{i}\right)+h_{3}^{j}\left(\varepsilon, \mathbf{A}, \mathbf{n}_{i}\right)
$$

for $\mathrm{j}=\{$ open, clos $\} ; h_{1}^{j}$ addresses isotropic-like damage effect that keeps the initial symmetry of the material, $h_{2}^{j}$ introduces weak-coupling with a directional dependence similar to the one derived in the isotropic context, whereas $h_{3}^{j}$ accounts for strong interaction between initial and damage induced anisotropies that may lead to a complex resulting elasticity. 
It is to note that functions $h$ and $g$ depend only on the virgin elastic properties, so as $W_{0}$. Moreover, mathematical conditions are satisfied by the potential $W$, especially the objectivity (since $h$ and $g$ depend on trace invariants) and the continuity of class $C^{1}$ that ensures the existence and continuity of the stress-strain response $\sigma=\frac{\partial W}{\partial \varepsilon}$ and of the scalar thermodynamic forces $F^{d_{i}}=-\frac{\partial W}{\partial d_{i}}$ corresponding to damage variables. Moreover, micromechanics provides a physical justification to the representation of activation-deactivation effects, regarding both the complex recovery phenomenon occurring at the closure of defects and the opening-closure criterion that derives from the cancellation of the normal jump displacement of microcracks.

\section{Damage evolution law}

Orientations $\mathbf{n}_{i}$ are fixed and systems of microcracks can only propagate along their respective own plane. Yet, note that a complex growth of the damage distribution can be taken into account by considering a sufficiently large number $N$ of systems.

In agreement with the assumption of dilute density, the damage evolution law has the same form for each system and is independent of others systems. The framework of generalized standard materials [14] is choosen to ensure the thermodynamical admissibility of the formulation. Assuming an adequate form of the pseudo-potential of dissipation, the normality rule provides the following damage criterion for the $\mathrm{i}^{\text {th }}$ system of microcracks (see details in $[12,15]$ ):

$$
f\left(F^{d_{i}}, d_{i}\right)=F^{d_{i}}-k_{0}\left(1+\eta d_{i}\right)
$$

with $\left(k_{0}, \eta\right)$ two scalar coefficients of the material. Introducing the consistency condition, the evolution law reads then:

$$
\dot{d}_{i}=\left\{\begin{array}{cl}
0, & \text { if } f \leq 0 \text { and } \dot{f}<0 \\
\sup \left\{0, \frac{1}{k_{0} \eta}\left(\frac{\partial F^{d_{i}}}{\partial \varepsilon}\right): \dot{\varepsilon}\right\}, & \text { if } f=0 \text { and } \dot{f}=0
\end{array} .\right.
$$

In the formulation, thermodynamic force $F^{d_{i}}$ is considered as the driving force of the damage process for the $i^{\text {th }}$ system. According to the expression of the thermodynamic potential, the damage evolution thus depends on the opening and closure of microcracks and on the interaction between anisotropies.

\section{Applications}

In this section, we intend to briefly demonstrate some of the model capabilities. Several materials have been considered to show various potential uses of this formulation.

First, Fig. 1 addresses the representation of elastic properties, through the distribution of the bulk modulus $\kappa$ for a carbon-epoxy composite [15]. At constant damage (fixed density variable d ), the model can thus account for the multilinear elasticity of brittle materials with degradation effects on elastic properties that depend on the status of microcracks (open or closed) and on their orientation regarding initial orthotropy. The axis case (when microcracks are aligned with one of the structural axis) leads to an orthotropic degradation of the bulk modulus, whether microcracks are open or closed (isotropic-like effect). Note in that particular case the total recovery of the bulk modulus 
(whatever the space direction) due to the cubic symmetry of the studied composite. On the other hand, the off-axis case illustrates the very complex resulting anisotropy obtained for open and closed microcracks. For directions $\mathbf{m}$ close to $\mathbf{e}_{1}$ (respectively $\mathbf{e}_{2}$ ), the damage deactivation leads to a value of the bulk modulus $\kappa(\mathbf{m})$ higher (resp. smaller) than for the virgin state. Similar features have already been obtained in the case of isotropic media for the Poisson ratio (resp. Young modulus) [16], and highlight the complex influence of defects in directions different from their normal, which is furthermore combined here with the contribution of initial anisotropy.

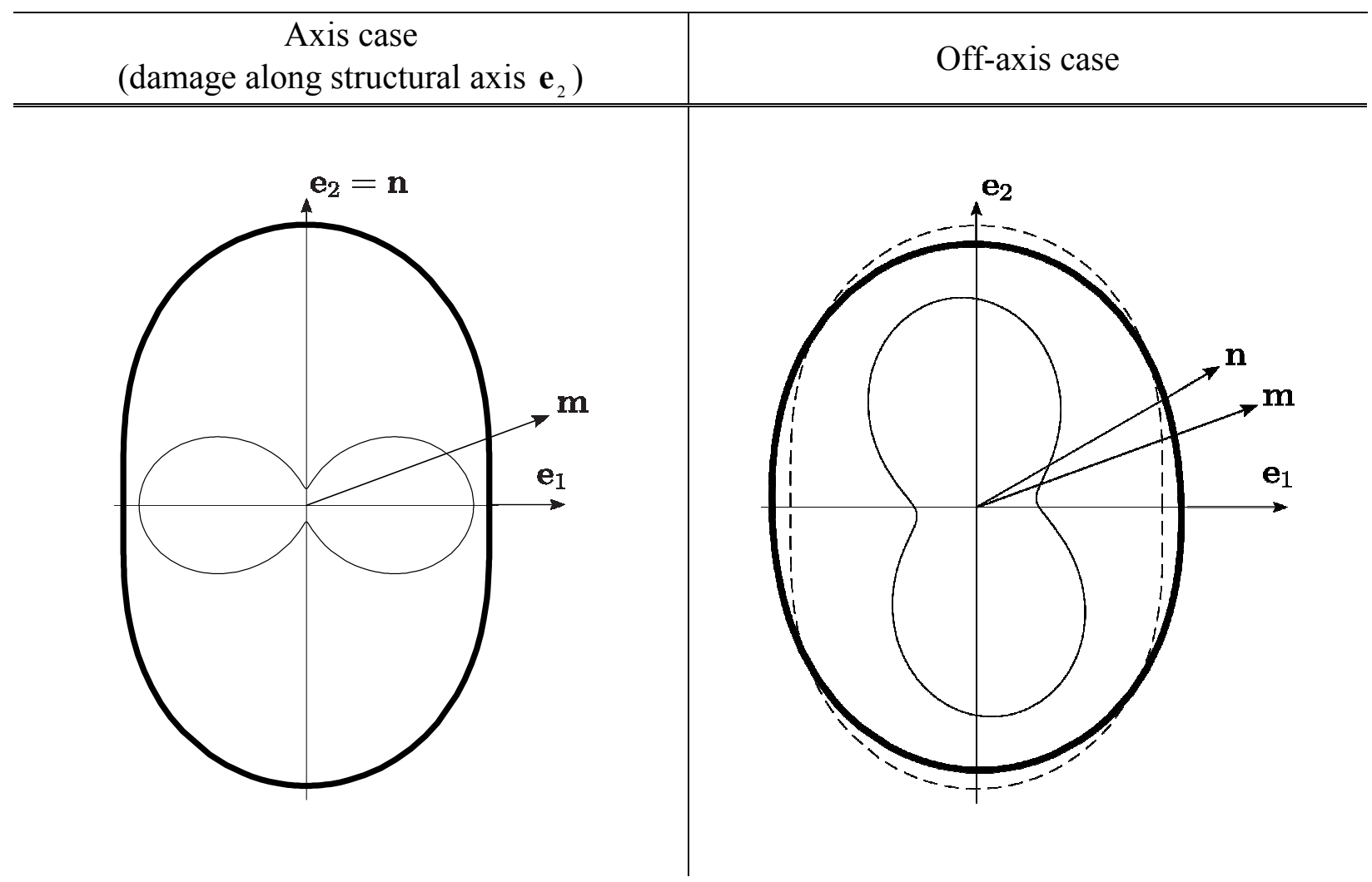

Fig. 1. Roses of the generalized bulk modulus $\kappa(\mathbf{m})$ in the direction of unit vector $\mathbf{m}$ for a carbonepoxy laminate weakened by a single array of microcracks of unit normal $\mathbf{n}$ (dashed line corresponds to virgin state, thin line to the open status, bold line to the closed status).

Second example aims at investigating some features of the model including the occurrence of dissipative process. The mechanical response of a ceramic composite ( $\mathrm{SiC}-\mathrm{SiC}$ ) under uniaxial tension load followed by compression is given in Fig. 2. Axis and off-axis loads have been investigated. This shows first that the model is able to describe the specific dissymmetric behavior between tensile and compressive loads of brittle materials. The different opening-closure state between these two situations explains the differences in damage evolution and in the yield stress: all microcracks are open during tensile load and some of them (those whose orientations are close to axial direction $\mathbf{y}$ ) get closed during compression. Such a test highlights also the influence of unilateral effects in the present orthotropic context. As shown by the evolution of the axial Young modulus, damage does not evolve during the unloading $(E(\mathbf{y})$ remains constant) and elastic properties recover to some extent their initial value (partial damage deactivation) when compressive load induces the closure of some microcracks. It should be noted that such jump in the stiffness remains compatible with the continuity of the stress-strain response. 


\section{Conclusion and perspectives}

The present complete constitutive model for 2D initially orthotropic materials offers very interesting perspectives for the representation of brittle damage. The rigorous mathematical and thermodynamical framework, associated with the physical justification provided by micromechanical considerations, appears as well founded. Some applications developed in this paper (see also [12,15]) illustrate capabilities of the model to account for complex interactions between primary anisotropy, induced anisotropy and unilateral effects.

The open nature of the model should also be underlined. Many aspects could then be integrated to this basic formulation such as coupling with plastic behavior or interactions between defects. For instance, an extension to the case of sedimentary rocks including the dependency of the damage criterion on loading direction has been proposed by [17]. Future works will now focus on the integration of another dissipative mechanism, namely the friction of the closed microcracks lips. The knowledge of the status of each microcracks system, by means of the opening-closure criterion, constitutes an important advantage for such development.

Axial stress-strain response

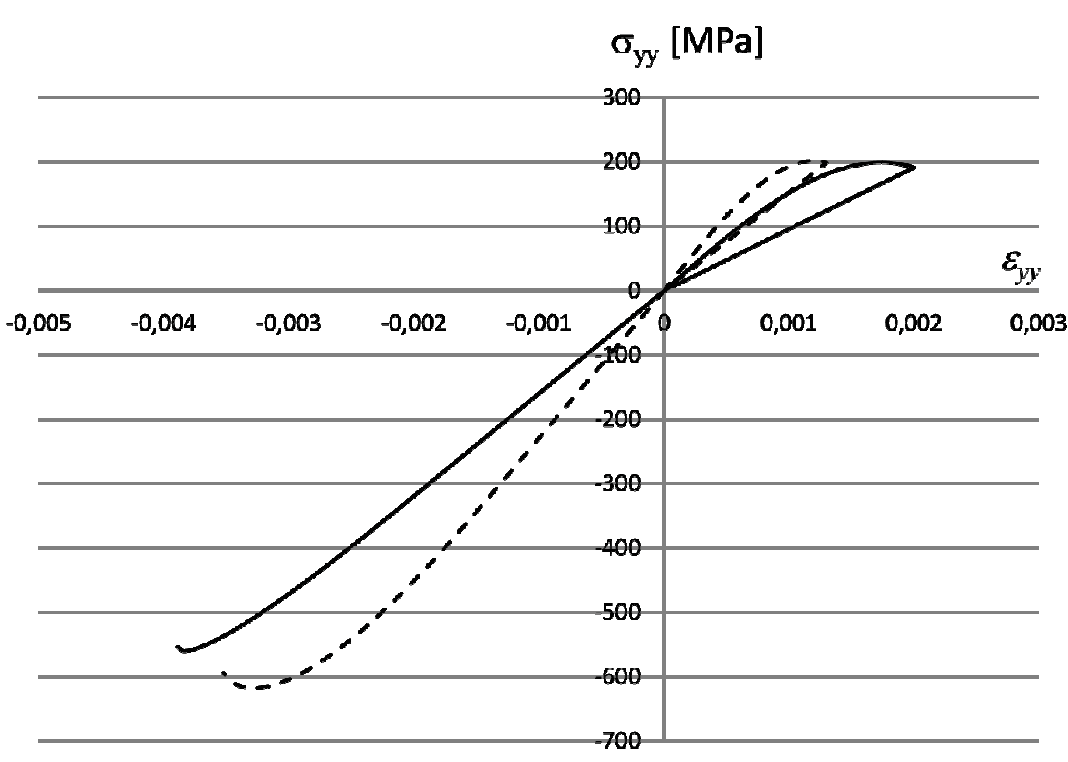

Evolution of the axial Young modulus according to the axial stress

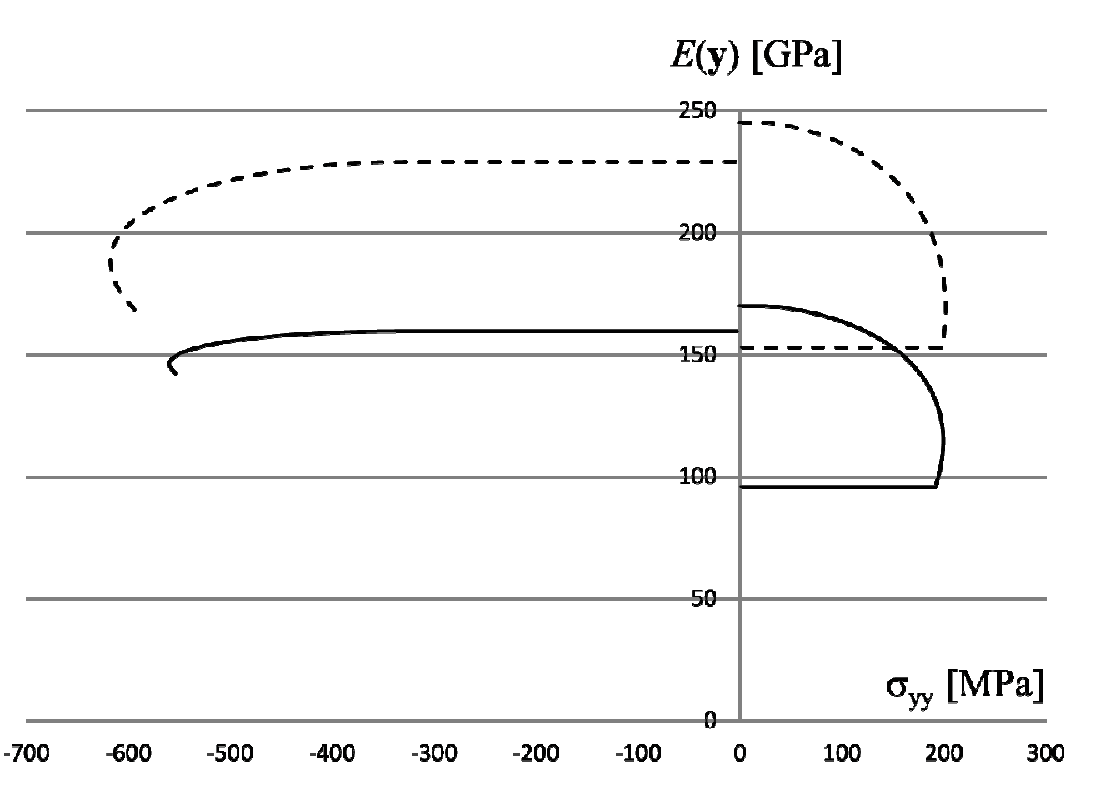

Fig. 2. Uniaxial tension load followed by compression along unit axis $\mathbf{y}$ on a ceramic composite (full line corresponds to axis load $\mathbf{y}=\mathbf{e}_{2}$, dashed line to an off-axis case). 


\section{References}

[1] S. Baste, C. Aristégui, Induced anisotropy and crack systems orientations of a ceramic matrix composite under off-principal axis, Mech. Mater. 29 (1998) 19-41.

[2] J.M. Morvan, S. Baste, Effect of the opening/closure of microcracks on the non linear behavior of a 2D C-SiC composite under cyclic loading, Int. J. Damage Mech 7 (1998) 381-402.

[3] C. Goidescu, H. Welemane, C. Garnier, M. Fazzini, R. Brault, E. Péronnet, S. Mistou, Damage investigation in CFRP composites using full-field measurement techniques : combination of digital image stereo-correlation, infrared thermography and X-ray tomography, Comp. Part B 48 (2013) 95105.

[4] H.W. Reinhardt, Fracture mechanics of an elastic softening material like concrete, Heron 29 (1984) 1-42.

[5] J.J. Liao, M.T. Yang, H.Y. Hsien, Direct tensile behavior of a transversely isotropic rock, Int. J. Rock Mech. Min. Sci. 34 (1997) 837-849.

[6] F. Homand, D. Hoxha, T. Belem, M.N. Pons, N. Hoteit, Geometric analysis of damaged microcracking in granites, Mech. Mater. 32 (2000) 361-376.

[7] J.L. Chaboche, On the difficulties associated with the active/passive unilateral condition, Int. J. Damage Mech. 1 (1992) 148-171.

[8] F. Cormery, H. Welemane, A critical review of some damage models with unilateral effect, Mech. Res. Comm. 29 (2002) 391-395.

[9] D. Krajcinovic, Damage mechanics: accomplishments, trends and needs, Int. J. Solids Struct. 37 (2000) 267-277.

[10] D. Krajcinovic, Micromechanical basis of phenomenological models, in: D. Krajcinovic, J. Lemaitre (Eds.), Continuum Damage Mechanics - Theory and Applications, Springer-Verlag, Wien, 1987, pp. 195-206.

[11] A. Dragon, F. Cormery, T. Desoyer, D. Halm, Localized failure analysis using damage models, in: R. Chambon et al. (Eds.), Localization and bifurcation theory for solids and rocks, Balkema, Rotterdam, 1994, pp. 127-140.

[12] C. Goidescu, H. Welemane, O. Pantalé, M. Karama, D. Kondo, Anisotropic unilateral damage with initial orthotropy: a micromechanics-based approach, Int. J. Damage Mech., in press.

[13] C. Goidescu, H. Welemane, D. Kondo, C. Gruescu, Microcracks closure effects in initially orthotropic materials, Eur. J. Mech. A/Solids 37 (2013) 172-184.

[14] P. Germain, QS Ngyuen, P. Suquet, Continuum thermodynamics, J. Appl. Mech. 50 (1983) 1010-1020.

[15] C. Goidescu, Caractérisation et modélisation de l'endommagement par microfissuration des composites stratifiés - Apports des mesures de champs et de l'homogénéisation, Thèse de l'Univ. de Toulouse- INP Toulouse, 2011.

[16] H. Welemane, F. Cormery, Some remarks on the damage unilateral effect modelling for microcracked materials, Int. J. Damage Mech. 11 (2002), pp. 65-86.

[17] S. Levasseur, H. Welemane, D. Kondo, A microcracks-induced damage model for initially anisotropic rocks accounting for microcracks closure, Int. J. Rock Mech. Mining Sci., in press. 